\title{
Process Improvement Proposal for the Reduction of Machine Setup Time in a Copper Transformation Company Using Lean Manufacturing Tools
}

\author{
Anthony Lora-Soto, Cristhoffer Morales-Silva, Jose Llontop-Jesus, \\ and Nestor Mamani ${ }^{(\square)}$ \\ Ingeniería Industrial, Universidad Peruana de Ciencias Aplicadas, \\ Lima 15023, Peru \\ \{u201511195, u201516979, jose.llontop, \\ pcsinmam\}@upc.edu.pe
}

\begin{abstract}
This study aimed to identify the causes of significant problems existing in the metallurgical sector, and a solution is proposed for the setup process. We detail the theoretical background of the processes in the lean manufacturing methodology, which will be applied to a rolling machine. Further, we provide a brief description of the company and the sector's problems. We describe success stories of companies that implemented various lean manufacturing tools. We also present some of the results achieved across sectors to gain an in-depth understanding of the technique and a practical support of the implemented model. Our proposal is based on the lean manufacturing methodology; tools such as Single Minute Exchanges of Dies, Kaizen, 5S, and value stream mapping (VSM) will be used to reduce setup times and to impact machine layout and productivity positively. We also show the implementation results of a pilot plan conducted in the company over a period of more than 3 months.
\end{abstract}

Keywords: Lean manufacturing $\cdot$ Setup $\cdot 5 \mathrm{~S} \cdot \mathrm{SMED} \cdot$ Availability $\cdot$ Metallurgy

\section{Introduction}

This study presents the case study of a company dedicated to the transformation of nonferrous metals. This company faces problems related to low productivity, an environment with poor order and cleanliness, and the lack of standardization in the setup process. These factors directly affect the process flow effectiveness, causing unnecessary motion, excessive worker downtime, and high setup times.

Our proposal for a solution is based on lean manufacturing tools. In the case study, we identified the process flow of the representative "busbar" product by means of a current state value stream mapping (VSM). Thus, we managed to identify the main area that experiences the lowest efficiency. Then, we mapped the process flow and started the implementation of specific tools such as SMED to standardize activities and reduce 
setup times and the $5 \mathrm{~S}$ method to improve the area order and reduce unnecessary motion during setup. The scope of this project addresses only the area found to have the lowest efficiency in the VSM. Furthermore, this study will focus on improvement to develop the production line's most representative products, known as busbar.

\section{Literature Review}

Lean manufacturing has significantly improved the performance of various industry processes [1]. For example, the $5 \mathrm{~S}$ tool was used to improve order and cleanliness based on Japanese philosophies [2]. Chiarini presented a case where a Lean Six Sigma methodology, namely $5 \mathrm{~S}$, was implemented, and a reduction by $21 \%$ was achieved in the setup time variability [3]. Rosa, Silva, Ferreira, and Campilho show that the combination of visual management and $5 \mathrm{~S}$ reduced setup times by $58 \%$ because of the order and discipline attained in the area after $5 \mathrm{~S}$ implementation [4]. Likewise, in the pharmaceutical sector, the use of the $5 \mathrm{~S}$ tool resulted in a reduction in batch setup times by $50 \%$ and an increase in productivity by $25 \%$ [5].

SMED was developed in the 1950s and focused mainly on minimizing setup time [6]. Rosmaini \& Mohd, both implemented SMED in a manufacturing plant for computer numerical control machines, and they managed to reduce setup times by $44 \%$ [7]. Furthermore, in a textile company, where only the SMED tool was implemented, the setup time of critical processes was reduced by 34.7\% [8]. SMED was also implemented in a plastic manufacturing company dealing with $4 \%$ production noncompliance, while the company policy did not allow for a value greater than $2 \%$. Therefore, after SMED implementation, the setup times were reduced by $29 \%$, and in turn, the production non-compliance indicator was reduced to $1.82 \%$ [9].

It is worth mentioning that SMED tool can be used along with other lean manufacturing tools. In the case study by Johnson and Prasad, they intended to reduce setup times using SMED in conjunction with 5S, Kanban, and VSM tools; they managed to reduce the setup times of the most critical production process by $77 \%$ [10]. Hamid and Yoong also successfully implemented SMED in conjunction with various tools such as standard work combination table, time measurement sheet, standard work chart, and standard operating procedure, achieving a $12 \%$ reduction in setup times [11].

\section{Methodology}

The study focuses on reducing the setup time in the metallurgical sector. Companies in this sector use several equipment items such as extrusion machines, rolling machines, or furnaces. Thus, the preparation time of these machines exceeds the standard time that should be achieved. To solve this problem, we used lean manufacturing tools such as SMED and 5S. The first one focused on reducing the machine preparation or setup time, while the second one sought to maintain an order in the operators' tasks, to achieve optimal movement flow. The following table shows the methodology used (Table 1). 
Table 1. Innovative technique steps

\begin{tabular}{l|l}
\hline Proposal & \multicolumn{2}{l}{$5 \mathrm{~S}$} \\
\hline Preliminary phase & \\
\hline SMED & \\
\hline Knowing the study process and areas & \\
\hline Identifying the current state & $5 \mathrm{~S}$ \\
\hline Identifying setup activities and name of areas, tools, etc. \\
\hline First phase & First S: Sort \\
\hline SMED & Second S: Set in Order \\
\hline Separating internal and external activities & \\
\hline Second phase & $5 \mathrm{~S}$ \\
\hline SMED & Third S: Shine \\
\hline Converting internal activities into external activities & Fourth S: Standardize \\
\hline Standardizing the new process & \\
\hline Kaizen event & \\
\hline Third phase & Fifth S: Sustain \\
\hline SMED & \\
\hline Control and monitoring of the new process &
\end{tabular}

The innovation of the technique is a result of joining the 5S and SMED steps because the two tools have the same guidelines and can yield very good results. This is also reinforced by the Kaizen tool, which promotes teamwork and leadership in the production lines. Thus, the implementation time of both tools is reduced, being performed simultaneously and not sequentially, which positively impacts the organization.

First, the preliminary phase shows the study process and areas and identifies the current state and the machine setup activities, the tools used, and other components. Further, we held a meeting with the operators and line supervisors to present the project and identify the company's current state.

Based on the information survey carried out in the process, we created a current state VSM and identified the rolling machine as a critical area of study.

Second, the project's first phase is used to analyze setup activities, classify internal and external activities, and implement sorting and setting in order.

Figure 1 shows the operators' movement flow. Consider from 1 to 7 the start and end zones of the machine. As can be seen, there is no standardized process, and there are unnecessary repetitive movements.

Third, the second phase involves the Kaizen tool, focusing on the new setup process standardization and the implementation of shining and standardizing.

Figure 2 shows in detail the process improvement by maintaining standardized activities and optimal movement flows. 


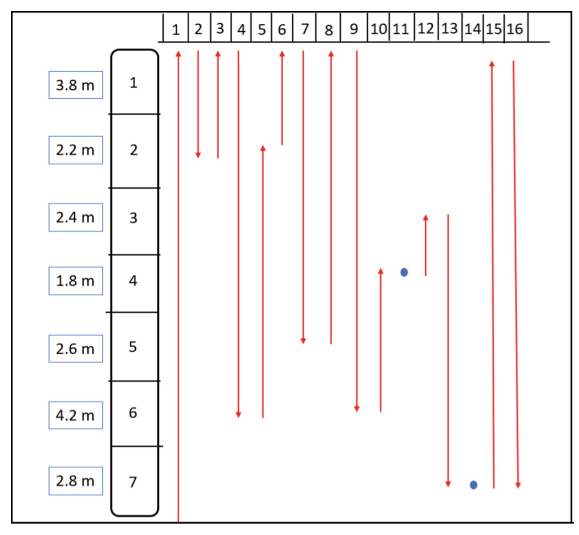

Fig. 1. Current setup process

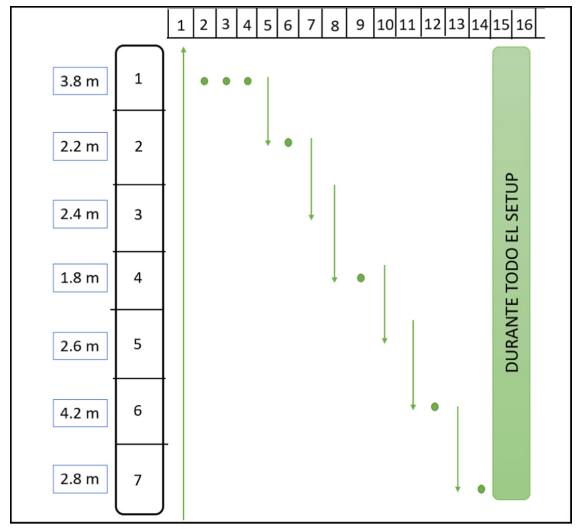

Fig. 2. Standardized setup process

The third phase consists of new process control and monitoring and result verification for both SMED and 5S. Then, the second Kaizen stage begins, which promotes teamwork.

Figure 3 shows the proposed VSM to assess the improvements made compared to the current state.

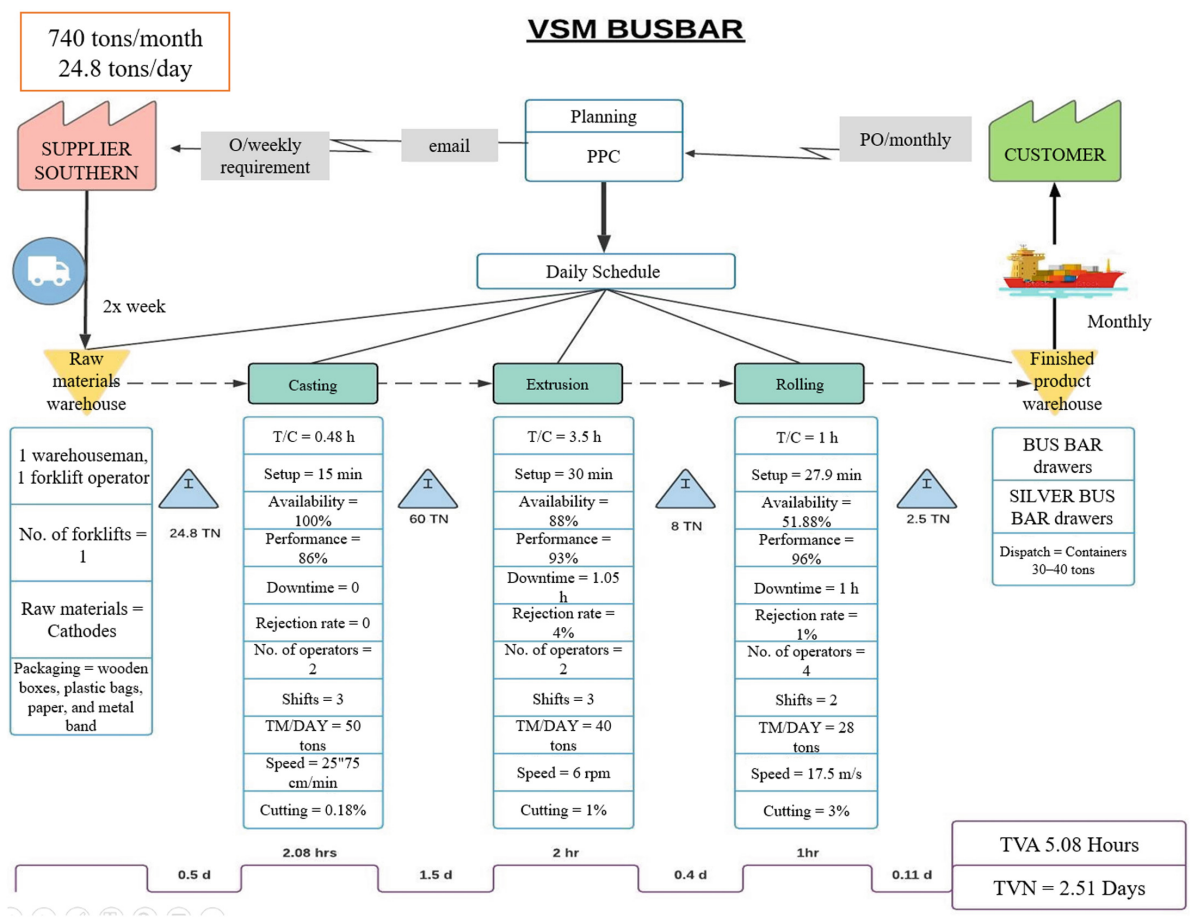

Fig. 3. Proposed VSM 


\section{Results}

First, setup times were reduced from 48.96 min to $28.44 \mathrm{~min}$, that is, a $42 \%$ reduction. Likewise, daily production increased from 20 tons to 29.8 tons per day (i.e., almost $50 \%$ of production). In addition, the machine availability indicator was improved from $45 \%$ to $62 \%$, generating a higher use of machine resources. Finally, the unnecessary motion in the setup process was entirely reduced, achieving an improvement of $68 \%$.

In terms of 5S, the initial area score was low (38.92\%). After implementing the 5S, we achieved an order and cleanliness score of almost $94 \%$, which consolidates the $5 \mathrm{~S}$ role in the improvement proposal. Furthermore, during the implementation, we discovered the solvent use factor with an amount of approximately 135 gallons per day. After establishing an order of activities, this was reduced to 70 gallons per month.

A productivity increase of $50 \%$, a motion reduction of $68 \%$, and a setup time reduction of $42 \%$ are the organization's expected values after the tool implementation. Thus, the improvement in productivity, equipment performance, and manpower efficiency show the importance of lean manufacturing tools in the industry. The summary of the results is shown in Table 2 .

Table 2. SMED \& 5S results

\begin{tabular}{l|l|l}
\hline Elements & $\begin{array}{l}\text { Before implementation } \\
\text { SMED \& 5S }\end{array}$ & $\begin{array}{l}\text { After implementation } \\
\text { SMED \& 5S }\end{array}$ \\
\hline Setup time & $48.96 \mathrm{~min}$ & $28.44 \mathrm{~min}$ \\
\hline Production & $20 \mathrm{tons} /$ day & $29.8 \mathrm{tons} /$ Day \\
\hline Availability & $45 \%$ & $62 \%$ \\
\hline Overtime (month) & $416 \mathrm{~h} /$ month & $0 \mathrm{~h} / \mathrm{month}$ \\
\hline Downtime (month) & $98.5 \mathrm{~h} /$ month & $6.4 \mathrm{~h} / \mathrm{month}$ \\
\hline Chemical solvent use (gal) & 135 gallons $/$ month & 70 gallons $/$ month \\
\hline Area cleaning (according to 5S) & $38.92 \%$ (Poor) & $93.94 \%$ (Excellent) \\
\hline Motion reduction & $170.2 \mathrm{~m} / \mathrm{setup}$ & $52.8 \mathrm{~m} / \mathrm{setup}$ \\
\hline
\end{tabular}

In summary, the positive impact generated by the improvement proposal can be quantified in terms of the following four aspects:

- Social: Improved work environment and motivation to perform daily activities

- Economic: Savings in overtime and increase in productivity both in indicator and monetary terms

- Environmental: Reduction of solvent use by $44 \%$

- Organizational: Effective communication, teamwork, leadership, and positive performance level 


\section{Conclusions}

The SMED implementation was focused on solving all the problems related to work standardization in the setup process, motion improvement, and setup time reduction. The 5S method was used to solve the problems associated with area order and cleanliness. Both tools used in conjunction with Kaizen and Kanban were key to initiate continuous improvement and to organize the setup components.

After an in-depth investigation in the company, we found problems related to productivity and efficiency that were mainly associated with low production because of excessive stoppages, such that more than $60 \%$ was attributed to setup, generating $45 \%$ of machine availability and incurring costs to fulfill orders. Thus, we conclude that by improving the setup process, not only machine availability but also productivity can be increased, and the number of stoppages due to setup can be reduced.

Because the setup time was reduced by $42 \%$, we achieved a $100 \%$ decrease in cost reduction overtime and a $50 \%$ increase in production. In addition, motion was reduced by almost $70 \%$. Finally, the machine availability was increased from $45 \%$ to $62 \%$, thus allowing a better use of machine resources. The daily production rate after implementation reached 29.8 tons per day, that is, an increase of $50 \%$.

With respect to area order and cleanliness, at first, we found disorder and a poor distribution of the setup process components. In addition, there was excessive use of certain components because there was not a specific order to use them. After the implementation of the methodology, the use of some components was improved, a reduction of $44 \%$ was achieved, and the area order and cleanliness was improved. Thus, we conclude that the problem identified in the company generated setup difficulties, which were solved through $5 \mathrm{~S}$ implementation.

\section{References}

1. Belhadi, A., Touriki, F.E., El Fezazi, S.: Benefits of adopting lean production on green performance of SMEs: a case study. Prod. Plan. Control 29, 873-894 (2018). https://doi.org/ 10.1080/09537287.2018.1490971

2. Kishimoto, K., Medina, G., Sotelo, F., Raymundo, C.: Application of lean manufacturing techniques to increase on-time deliveries: case study of a metalworking company with a make-to-order environment in Peru. In: Ahram, T., Taiar, R., Colson, S., Choplin, A. (eds.) IHIET 2019. AISC, vol. 1018, pp. 952-958. Springer, Cham (2020). https://doi.org/10.1007/ 978-3-030-25629-6_148

3. Chiaini, A.: Improvement of OEE performance using a Lean Six Sigma approach: an Italian manufacturing case study. Int. J. Prod. Qual. Manage. 16, 416-433 (2015)

4. Rosa, C., Silva, F.J.G., Ferreira, L.P., Campilho, R.: SMED methodology: the reduction of setup times for Steel Wire-Rope assembly lines in the automotive industry. Procedia Manuf. 13, 1034-1042 (2017). https://doi.org/10.1016/j.promfg.2017.09.110

5. Bevilacqua, M., Ciarapica, F., De Sanctis, I., et al.: A Changeover Time Reduction through an integration of lean practices: a case study from pharmaceutical sector. Assembly Autom. 35(1), 22-34 (2015). https://doi.org/10.1108/AA-05-2014-035

6. Shingo, S.: A Revolution in Manufacturing: The SMED System. CRC Press, Boca Raton (1985) 
7. Ahmad, R., Soberi, M.S.F.: Changeover process improvement based on modified SMED method and other process improvement tools application: an improvement project of 5-axis CNC machine operation in advanced composite manufacturing industry. Int. J. Adv. Manuf. Technol. 94(1), 433-450 (2017). https://doi.org/10.1007/s00170-017-0827-7

8. Díaz-Reza, J., García-Alcaraz, J., Martínez-Loya, V., Blanco, J., Jiménez, E., Avelar-Sosa, L.: The effect of SMED on benefits gained in maquiladora industry. Sustainability $\mathbf{8}, 1237$ (2016)

9. Reyes, S., Jeampiere, A., Castro, S., Fernanda, R.: Application of lean techniques to reduce preparation times: case study of a Peruvian plastic company. Int. J. Appl. Eng. Res. 12(23), 12 (2017)

10. Johnson, A., Prasad, S., Sharma, A.K.: Manufacturing lead time reduction in a scaffold making industry using lean manufacturing techniques-a case study. Int. J. Mech. Eng. Technol. 8(2), 12 (2017)

11. Puvanasvaran, A.P., Ab. Hamid, M.N.H., Yoong, S.S.: Cycle time reduction for coil setup process through standard work case study in ceramic industry. ARPN J. Eng. Appl. Sci. 13 (1), 210-220 (2018) 